\title{
The big leap: How to move from what is agreed and done to what needs to happen
}

\author{
Eeva Furman* \\ Finnish Environment Institute SYKE, Latokartanonkaari 11, Helsinki, Finland
}

\begin{abstract}
In this article, I tell about the key findings and action points from the Global sustainable development report 2019 - Future is Now (GSDR2019) - and raise, based on the report, messages and recommendations for the academic publishing community for consideration and action. The Agenda2030 for sustainable development was signed by all UN member countries in 2015. It is an ambitious political framework to transform the world into a safe and just place. Based on the GSDR2019, only little progress had taken place until 2019. To speed up the progress in a way that makes durable changes towards sustainable development, there is a need to identify the interlinkages between the various goals and targets and push transformation in six key societal systems side by side. To make this happen, four types of levers need to work in an integrated manner. To ensure this, universal science capacity is required, with an emphasis on sustainability science. The academic publishers play an important role here. Open access, searchable databases and syntheses are highly needed.
\end{abstract}

Keywords: Sustainable development, Agenda2030, sustainability transformation, open access, science capacity, interlinkages

\section{Intro}

When the United Nation (UN) 2030Agenda for sustainable development was signed in 2015 by all UN member countries, a high inspiration was blooming all over the world. Several actors, including countries and cities, but also businesses, NGOs and researchers got mobilized and initiated action to push forward the sustainable development goals (SDGs). The challenges of the implementation were recognized by all countries at an early stage and in 2016 the member countries decided to have a science report every four years to elucidate the state of sustainable development globally and indicate how the world should move forward. The first report was delivered to the heads of UN member nations in September 2019, during the UN Summit. The message was clear: the situation is serious but there is a way forward.

\section{Interlinkages}

Until today, only little progress has taken place since 2015, in some of the goals no progress has been seen and the most worrying fact is that issues such as growing inequalities, biodiversity loss, climate change and the waste problem are still on negative trends. Each of these are major challenges as such, but

*E-mail: eeva.furman@ymparisto.fi. 


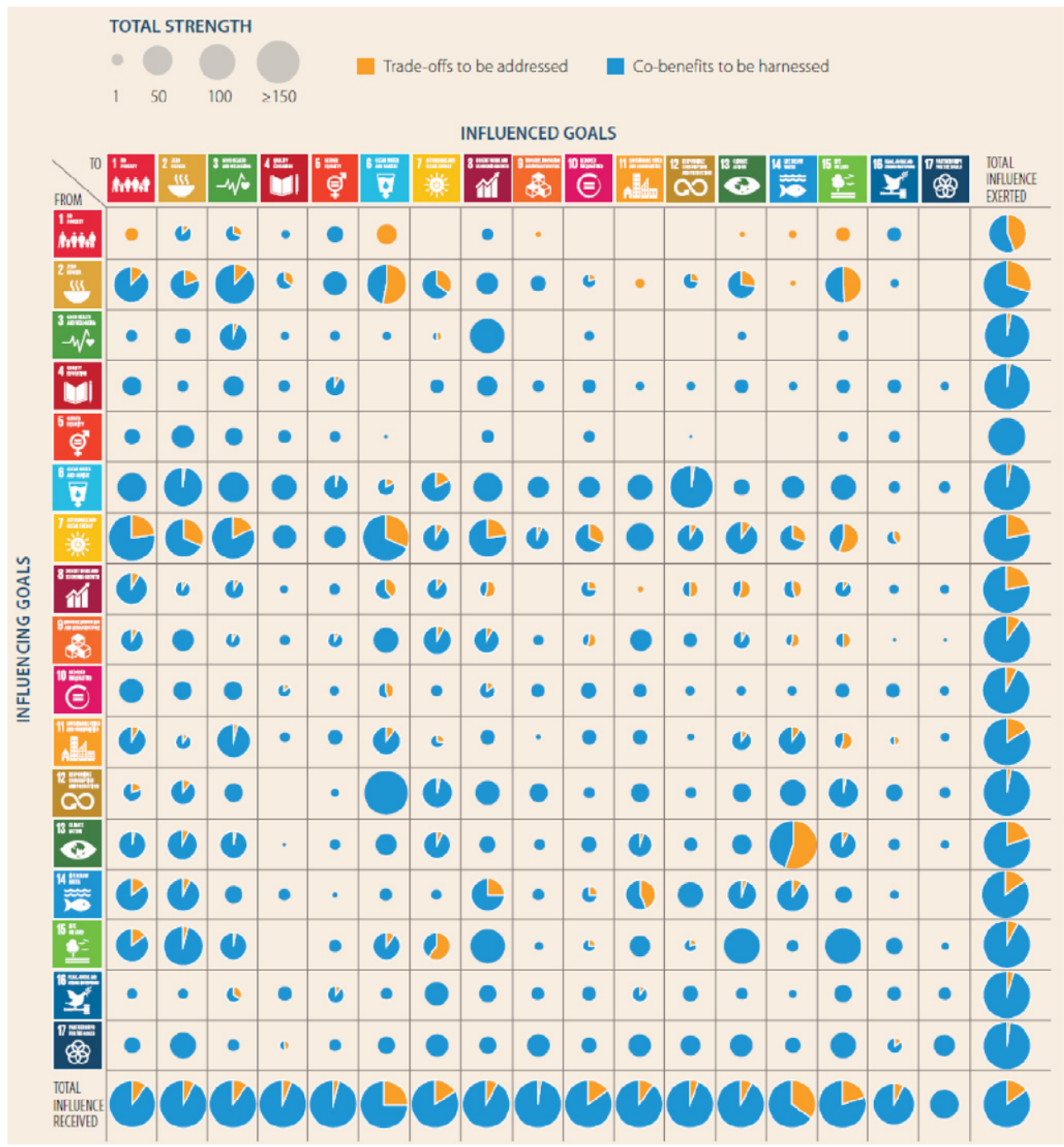

Fig 1. This figure from the GSDR2019 shows the interlinkages between the sustainable development goals based on existing scientific literature. The size of the circle shows the volume of studies to which the analysis bases for each interlinkage, on global interlinkages. The co-benefits are shown in blue while the trade-offs are indicated with orange color. See the report for more details on the methodology.

due to their linkages to each other and to all sustainable development goals the lack of progress in these issues hampers the development of the entire Agenda2030.

This shows clearly the interconnected characteristics of sustainable development. This means that as the problems are connected, likewise are the actions. Actions taken for one goal most likely impacts one or several of the other goals, as well. These impacts can be positive leading to co-benefits in reaching the goals, but they can also be negative, where another goal becomes harder to reach due to actions taken towards or progress in the other one.

Both the co-benefits as well as trade-offs should be identified before decisions are made by analyzing what kind of linkages there are between the goal in question and all other goals, so that the optimal actions 


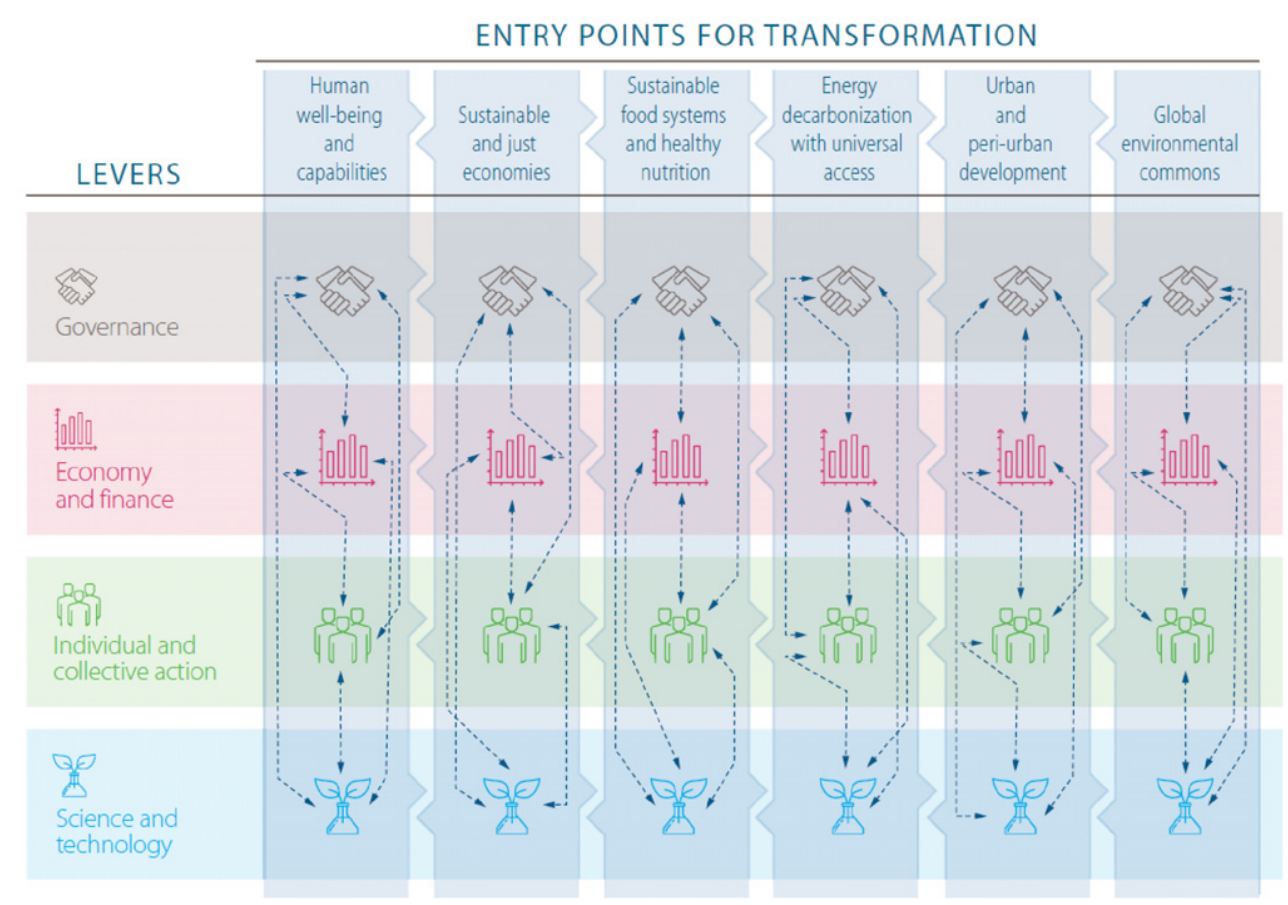

Fig 2. This figure from GSDR2019 shows the operational roadmap with context specific pathways to transformation towards sustainability, recommended for every country to apply. The leavers push in an integrated way forward the six entry points for transformation. Each country can taylor the levers to their demands and culture. For more detail, see the full report.

can be decided upon or necessary actions could be planned in advance, either to foster collaboration when co-benefits are in question or as support mechanisms when trade-offs are expected to arise. For example, if the use of fossil fuel, due to eg. climate taxation, becomes so expensive that a field of industry in a certain location collapses, support mechanisms for those people who are losing jobs need to be planned in advance to ensure them to get new sources of income.

Too often, science is lacking when knowledge on the interlinkages are needed. This type of research is highly in demand for enhancing sustainable development. The academic publishers can take an active role as drivers of research on interlinkages as well as making research on interlinkages visible. One effective way to support decision makers with scientific knowledge on interlinkages is to make searchable databases available, in open access terms (Fig. 1).

In addition to the interlinkages between goals, the challenges and goals link also different countries, different regions and different parts of the world together. These bonds are formed through flows of goods, information, people, money, and many other issues, not the least lifestyles and things that are trendy. This is the way our lives and organizations of our societies function today.

The third key dimension of interlinkages raises how various actors in societies are linked with each other through the challenges we face as well as combatting them. Therefore, the direction of development is not in the hands of public sector only, nor of the business world, but many actors are involved, and they interact, consciously or unconsciously. The most active in enhancing sustainable development have been cities and the business community but also science community and the civil society, in addition to governments on national, regional and global level have taken important steps. 


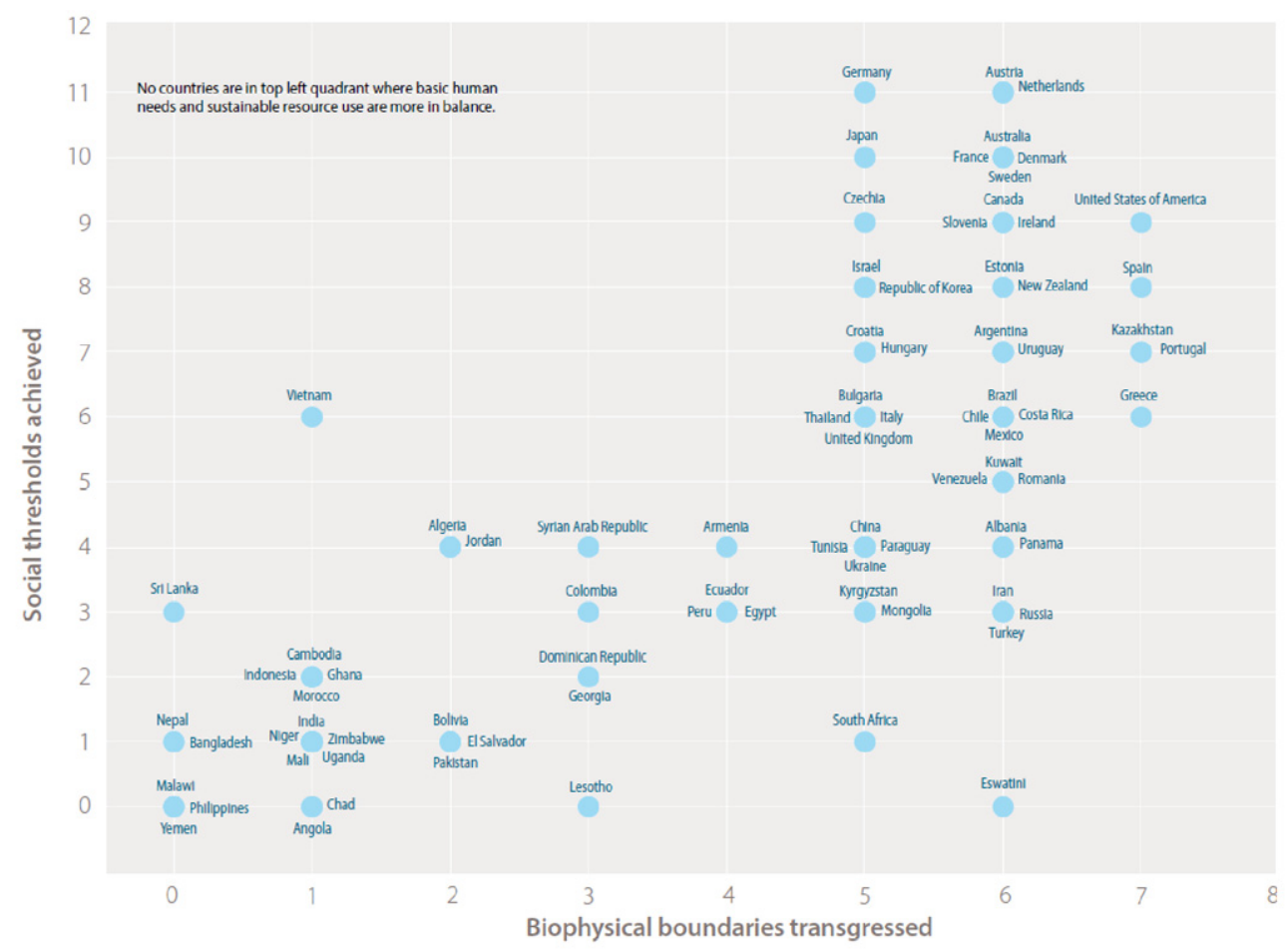

Fig 3. Shows how different countries are in very different situations in relation to the various sustainable development goals (GSDR2019).

Many, unfortunately, also enhance the unsustainable development, which is mainly due to the fact, that there are also winners of today's situation, and losers on the other hand, as being desperate, follow the single solutions trap offered by politicians building on nationalism and populism the approaches of which overlook interlinkages and the wicked manner of these challenges and require deeper analyses of the situation.

This causes friction and hampers the steps now needed. Recent science shows, however, that the risk of escalations in societal and environmental processes grows all the time and this challenges the wellbeing globally not leaving out the winners of today. For example, rising inequalities does not deliver sustainable economic growth nor a way out from poverty.

\section{Way forward}

To move forward impactfully, the GSDR2019 recommends all countries and global institutions to implement a framework for pathways to sustainable development, which builds on transformations in six societal systems as entry points (1) Human wellbeing and capabilities, (2) Sustainable and just economies, (3) Sustainable food systems and healthy nutrition, (4) Energy decarbonization and universal access, (5) Urban and peri-urban development, and (6) Global environmental commons.

There is no space to prioritize these transformations as also they are intertwined. To be able to push these transformations forward simultaneously, effectively and fast but without leaving no-one behind, four 
Table 1

Recommendations to the academic publishers community on how to contribute to the implementation of the Agenda2030

1. Enhance open journal and database access especially in the developing countries to inform students and scientists in universities and research institutions.

2. Contribute to the development of universal science capacity through reward systems for those papers in which the authorship is shared between North and South on fair terms.

3. Establish South-North sustainability science journal.

4. Establish South-South social science sustainability journal.

5. Provide special thematic issues targeted to and open for policy makers.

6. Encourage the youth into sustainability science with special issues on open access terms.

7. Develop filtering systems and database search mechanisms to show for interlinkages of SDGs and to separate various geographical regions.

8. Publish by invitation-created meta-analyses and syntheses of sustainability issues.

9. Raise funds for access to science in the developing countries.

10. Promote major funding mechanisms for universal sustainability science.

levers: governance, economy and finance, individual and collective action, and science and technology are needed. The levers need to be used in an integrative way so that they push and pull each other to enable transformations to move development to the same direction (Fig. 2).

This calls upon a major change in leadership, in the UN institutions, various governments, and in all cities around the world. It also urges NGOs and businesses to put sustainability development as the basis of all their planning, budgeting and decision making, by using the systems transformations and integrated leavers as the roadmap.

As countries and other institutions are in very different situations concerning their transformative needs and potentials, as well as their cultural characteristics, the way levers are used for the six pathways for transformation needs to be adapted accordingly (Fig. 3).

For the transformative roadmap to materialize, also science needs to go through a major transformation. To be able to tackle with (1) the interlinkages, (2) the flows across borders and (3) the power structures and to (4) develop knowledge-based processes through which the transformations are planned and applied, a universal science capacity and an upscaled input into sustainability science, is needed.

This notion includes the need for stronger mechanisms and platforms for science-policy-society to inform already existing knowledge but also mechanisms to produce and deliver new understanding on the crucial issues mentioned: interlinkages, power structures and other enablers of transformations from experimentation in practice, innovated together with actors in question, and simultaneously taking sustainability science to the next level.

Presently, science capacity is highly concentrated to the developed countries and sustainability science is only one strain of research among many. Challenges arise when taking into notion, that majority of the research funding comes from private sources, which does not necessarily direct research resources to focus on systems and sustainability, and open science [2].

\section{Mobilizing the academic publishers}

The academic publishing community has already taken initiatives to support transformation in science towards sustainable goals, practices and contributions. However, further action is needed to ensure this 
move that is so crucial for humanity. Table 1 provides recommendations to the community of academic publishers on ways to enhance the transformation towards sustainable development.

\section{Acknowledgements}

I want to thank the Independent group of scientists (IGS) who wrote the global sustainable development report (GSDR2019) as well as the support group of the writing process for constructive discussions on the role of academic publishers for enhancing the implementation of the Agenda2030. The APE conference 2020 was the main driving force for motivation to write this paper.

\section{References}

[1] P. Eloundou-Enyegue, E.G. Foli, E. Furman, A. Glassman, G. Hernandez Licona, E.M. Kim, W. Lutz, P. Messerli, J.-P. Moatti, E. Murniningtyas, K. Richardson, M. Saidam, D. Smith, J. Kazimieras Staniškis and J.-P. van Ypersele, Global Sustainable Development Report 2019. The future is now; science for achieving sustainable development. New York: Division for sustainable development knowledge platform, Department of Economic and Social Affairs, United Nations Secretariat Building, 2019. - 216 s. https://sustainabledevelopment.un.org/gsdr2019.

[2] P. Messerli, E.M. Kim, W. Lutz, J.-P. Moatti, K. Richardson, M. Saidam, D. Smith, P. Eloundou-Enyegue, E. Foli, A. Glassman, G. Hernandez Licona, E. Murniningtyas, J. Kazimieras Staniškis, J.-P. van Ypersele and E. Furman, Expansion of sustainability science needed for the SDGs, Nature Sustainability 2(October) (2019), 892-894 www.nature.com/natsustain. 